\title{
British government releases plans to cut air pollution by 2005
}

London. The UK government has unveiled its National Air Quality Strategy and promised that by 2005 British cities will be rid of smog and dangerous levels of air pollutants. The strategy is seen as a key attempt by the government to set out its 'green'

\section{IMAGE UNAVAILABLE FOR COPYRIGHT REASONS}

\section{Yorkshire smog cloaks Sheffield.}

credentials, ahead of the opposition Labour party, which has yet to formulate its own proposals.

The strategy document sets out to reduce atmospheric concentrations of eight classes of pollutants that are considered partly to blame for rising cases of asthma and premature deaths during smog episodes. The targets were recommended over the past two years by the government's Expert Panel on Air Quality Standards (EPAQS).

The strategy, however, does not spell out how the objectives will be met. For example, it does not say how the government will reduce concentrations of the tiny soot 'particulates' from vehicle exhaust emissions that are linked to heart attacks, and breathing difficulties. The UK Department of Health estimates that particulates are responsible for several thousand premature deaths each year and 10-20,000 hospital admissions.

The government believes its current policies will meet targets to reduce concentrations of four of the pollutants: carbon monoxide, benzene, 1.3 butadiene and lead. However, it acknowledges that "additional measures" - yet to be announced - will be needed to meet targets for the remaining four: nitrogen dioxide, particulates, ozone and sulphur dioxide.

The air quality strategy also indicates the government will rely on a mix of local traffic regulation and clean technology - as opposed to new taxes and bans on the use of cars - to achieve its targets.
Local authorities will be given new powers to pedestrianize streets. They may also be allowed to penalize drivers with suspect emissions as well as those found parking in pollution hot-spots. Industry, meanwhile, will be encouraged to develop new emissions technologies, such as catalytic converters for diesel engines.

John Gummer, secretary of state for the environment, says that the responsibility for reducing pollution is a "partnership" in which the public also has a stake. Gummer

$\overline{\overline{\bar{M}}}$ says he envisages families owning fewer cars and using them less often.

The document has had a mixed reception. The oil and motoring lobbies are relieved at the decision not to levy more taxes, and to encourage new technologies instead. The decision to defer measures to curb diesel engine exhaust fumes, which account for 80 per cent of particulate matter emissions from road traffic, will also be welcomed by the road haulage lobby.

But Sir John Houghton, chairman of the Royal Commission on Environmental Pollution, believes the government should not delay measures to cut diesel emissions. A 1994 report from the Commission on transport and the environment suggested incentives be given to owners of old diesels to buy newer and cleaner ones. "This is an important issue, which the government does not seem to have picked up," says Houghton.

The strategy acknowledges that emissions of particulates and nitrogen oxides can be cut by up to 70 per cent for each diesel vehicle that is converted to run on alternative fuels such as compressed natural gas or liquefied petroleum gas. Roy Harrison, professor of environmental health at the University of Birmingham, and a member of EPAQS, says such changes ought to be encouraged, and will require minimal modifications to engines.

Environmental groups and opposition political parties have dismissed the strategy as 'too little, too late'. The Labour party says it is an acknowledgement that previous policies - under Margaret Thatcher - to invest in the building of roads as opposed to public transport, were a mistake. But Labour has yet to unveil its own proposals, which are unlikely to include measures such as taxation, because of the opposition party's determination not to announce new taxes in the run-up to a general election.

Tony Bosworth, air pollution campaigner for Friends of the Earth, says the government strategy does not address the main cause of air pollution: "too much traffic". The numbers of cars, he says, are projected to double by 2025 . Reducing this rate of growth, he believes, should be a higher priority.

Ehsan Masood

\section{France told to put brake on biofuels}

Paris. France's planned legislation to curb traffic pollution has been criticized by the French Academy of Sciences, which says that adding oxygenated compounds, such as biofuels, to conventional fuels may create as many problems as it solves.

The addition of these compounds - such as those derived from rapeseed, wheat and beetroot - to fuel would become compulsory in 2000 under legislation to come before the national assembly in the autumn. The proposal, which is a major plank of the legislation, has been enthusiastically supported by the public, ecologists and, not surprisingly, farmers.

But the Green appeal loses some of its shine upon closer examination, says a preliminary academy report on traffic pollution. It argues that, although the addition of such compounds to fuels in the United States has permitted reductions in carbon dioxide and unburnt hydrocarbons, this experience cannot be directly transposed to Europe. This is because of differences in engine designs, cli- mate and the way cities are built.

Addition of oxygenated derivatives would help to reduce acid pollution, says the report, because the derivatives contain no sulphur, and would cut exhaust levels of benzene, a carcinogen. But it would produce aldehydes that may also be carcinogenic, it says, as well as the nitrogen oxides involved in the formation of ozone. The report contests the wisdom of adding these derivatives to fuel, given the "poorly understood" risks of aldehyde emissions.

The academy concludes that the measure with the most immediate impact on air pollution would be to encourage people to trade in their old vehicles for newer ones fitted with catalytic converters.

The report is also enthusiastic about vehicles running on liquefied gas and electricity. It recommends that gas should be encouraged in fleets of light and heavy goods vehicles and buses, and that greater support should be given to efforts to develop electric vehicles.

Declan Butler 